\title{
A new species of Epopostruma (Hymenoptera: Formicidae) from monsoonal Australia
}

\author{
MAGEN J. PETTIT ${ }^{1} \&$ ALAN N. ANDERSEN ${ }^{2}$ \\ ${ }^{1}$ CSIRO Health \& Biosecurity, PMB 44, Winnellie, NT 0822, Australia. \\ ”" magen.pettit@csiro.au; (10 https://orcid.org/0000-0001-5799-3515 \\ ${ }^{2}$ Research Institute for the Environment and Livelihoods, Charles Darwin University, Darwin, NT 0909, Australia. \\ झ"alan.andersen@cdu.edu.au; (1) https://orcid.org/0000-0003-1487-3323
}

\begin{abstract}
Epopostruma is an uncommon genus of myrmicine ants endemic to relatively mesic regions of southern and eastern Australia. Here we describe a new species recently recorded from the 'Top End' of Australia's Northern Territory, E. topendi sp. n. from Melville Island and Nitmiluk National Park. The new species is known from one specimen from each of two sites in the Australian monsoonal tropics, the only records of the genus from this region. This addition brings the number of described species of Epopostruma to twenty.
\end{abstract}

Key words: Myrmicine, Epopostruma, new species, Top End, monsoonal tropics, Bassian

\section{Introduction}

The myrmicine genus Epopostruma Forel, 1895 is restricted to Australia where it has a Bassian distribution, occurring primarily in heathlands, woodlands and open forests of the southeast and southwest. The genus comprises 19 described species (Shattuck 2000, 2007), almost all of which have been rarely collected due to their inconspicuous nature, cryptic habits, small colony sizes and often nocturnal foraging (Shattuck 1999). Indeed, eight of the species are known from only one or two collections (Shattuck 2000, 2007).

A recent analysis of the ant fauna of the 'Top End' (north of Katherine) of the Northern Territory (NT) lists two undescribed specimens of Epopostruma (Andersen et al. 2018), which represents the first published record of the genus in Australia's monsoonal tropics, the savanna landscapes of the northern third of the continent. Anonychomyrma, Notoncus and Dolichoderus are other Bassian (cool temperate) genera occurring in the Top End (Andersen et al. 2018) but unknown elsewhere in monsoonal Australia, suggesting that the region might be a refuge for genera that were previously more widely distributed across northern Australia. Here we describe the NT specimens as a new species of Epopostruma, bringing the total number of described species in the genus to twenty.

\section{Measurements}

The following measurements (in millimetres) and indices were recorded, following Shattuck (2000):

ML Straight-line length of the closed mandibles, measured in the same plane as HL, from the mandibular apex to the anterior clypeal margin, or to a transverse line connecting the anterior- most points in those taxa where the margin is concave medially

HL Maximum head length in full face view, measured from the anterior clypeal margin to the midpoint of a line drawn across the posterior margin of the head

HW Maximum head width in full face view, excluding eyes

PW Maximum pronotal width in dorsal view (excluding projecting spines, tubercles or other cuticular prominences at the pronotal humeral angles)

SL Length of the scape (first antennal segment) excluding the basal constriction and condylar bulb 
$\mathrm{AL}$ (= Weber's Length) Diagonal length of mesosoma in profile from the point at which the pronotum meets the cervical shield to the posterior base angle of the metapleuron

TL Total length of outstretched ant from mandibular apex to the gastral apex; when measured in profile the sum of ML $+\mathrm{HL}+\mathrm{AL}+$ lengths of waist segments + length of gaster

CI (cephalic index) HW x 100/HL

MI (mandible index) ML $x$ 100/HL

SI (scape index) SL x 100/HW

All measurements were taken using a Zeiss stereomicroscope with an eyepiece calibrated against a stage micrometer.

\section{Epopostruma Forel, 1895}

\section{Epopostruma topendi sp. $\mathrm{n}$.}

(Figs 1a-d)

Holotype worker: Australia, Northern Territory, Nitmiluk National Park $14^{\circ} 14^{\prime} 02^{\prime \prime}$ S, 132 $12^{\circ} 28^{\prime \prime}$ E, April-May 2015, S. Oberprieler, pitfall trap, sandstone woodland. Unique specimen identifier 32163815.

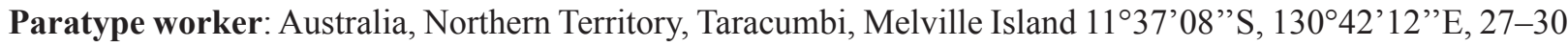
Jul 2009, M. Pettit, pitfall trap, savanna woodland. Unique specimen identifier 32 163816. Holotype and Paratype deposited at Australian National Insect Collection, Canberra, ACT, Australia.
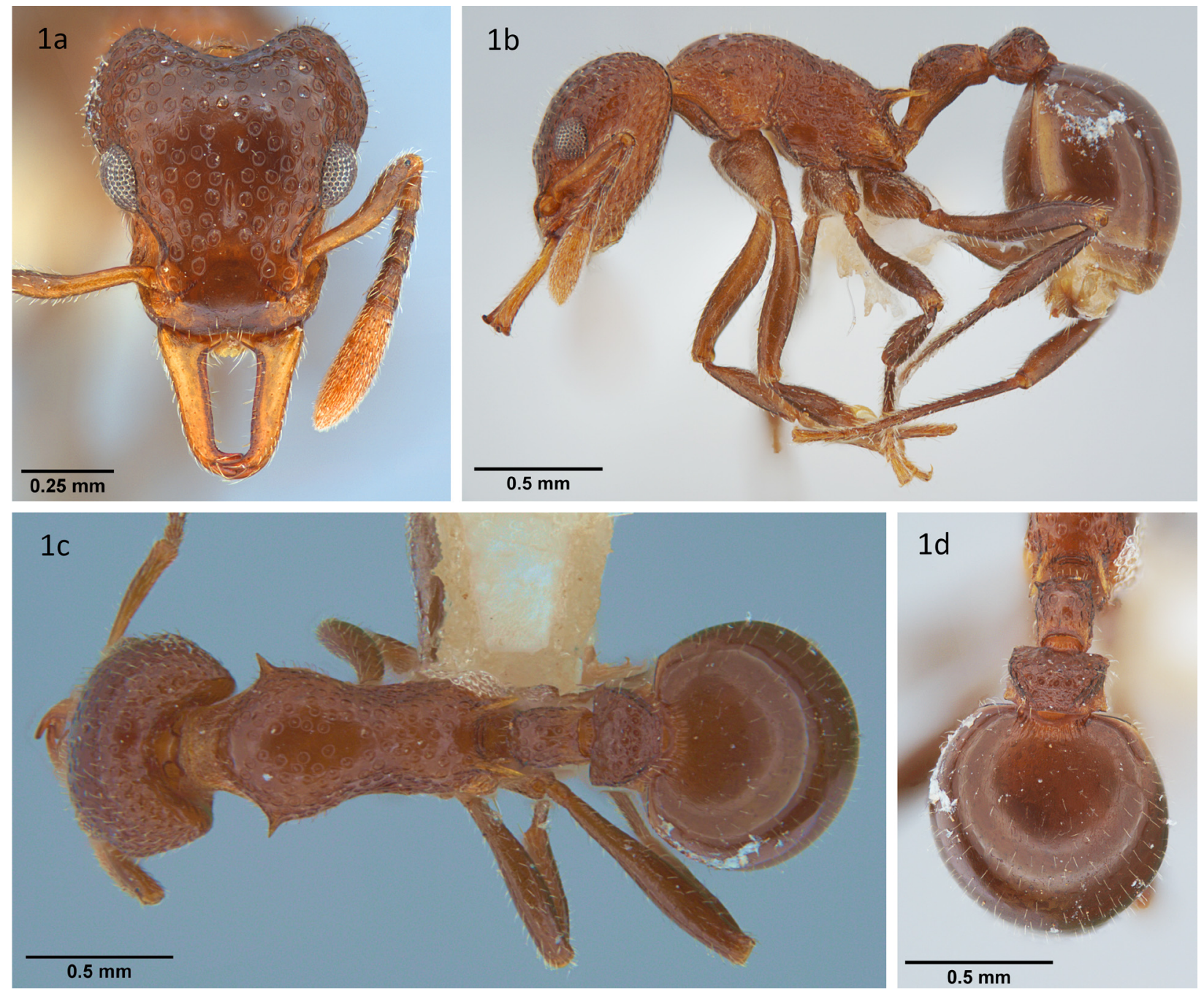

FIGURE 1. Epopostruma topendi sp. n. holotype worker: (a) frontal head full face; (b) lateral view; (c) dorsal view; (d) petiole and postpetiole in dorsal view. 
Description: Holotype worker. TL 3.9; HL 0.81; HW 0.75; CI 93; ML 0.43; MI 53; SL 0.49; SI 65; PW 0.51 AL 1.01. In full-face view the lateral margin of the head between the eye and the occipital lobe slightly angular. Posterior margin of head deeply concave, with occipital lobes somewhat angled posteriorly. Pronotal spines present, elongate. Posterior section of mesonotum in approximately the same plane as the dorsal face of propodeum, the junction of these plates forming a very shallow depression. Posterior face of propodeum with thin flanges between bases of spines and propodeal lobes. Petiolar node with a pair of conspicuous, semi-erect denticles on the dorsolateral margins. In dorsal view, petiolar node narrow and parallel-sided. Anterior face of the postpetiole distinctively flattened, with angular lateral margins. Sides of postpetiole not expanded laterally. In dorsal view, postpetiole bluntly square anterolaterally and conspicuously dentate posterolaterally, with denticles broader than long. Dorsum of petiole, postpetiole and gaster with numerous short, blunt and often clubbed erect hairs. Head, mesosoma, petiole and postpetiole with well-spaced foveolae and to a large extent smooth and shiny, especially dorsally. First gastral tergite entirely smooth. Colour uniformly reddish-brown.

Etymology: The name is a non-Latin noun (and thus invariant), named after the Top End region of the Northern Territory in which the specimens were recorded.

\section{Discussion}

Epopostruma topendi $\mathbf{s p .} \mathbf{n}$. is a rare species currently known from two single specimens collected in different remote regions in the Top End of the Northern Territory. They lack lateral expansions of the postpetiole, and so belong to the E. quadrispinosa (Forel) group (Shattuck 2000). The presence of pronounced posterolateral but not anterolateral teeth on the postpetiole, along with an entirely smooth gaster, indicates that they are closely allied to E. areosylva Shattuck from New South Wales and southeastern Queensland, from which they are readily distinguished by their generally smooth appearance (especially dorsally) and dentate rather than spinose petiole. The only representatives of Epopostruma previously known from far northern Australia are E. quadrispinosa (Forel) and E. monstrosa Viehmeyer, both occurring in the wet tropics of North Queensland (Shattuck 2000). They are readily distinguished from E. topendi by their coarser sculpture, lack of posterolateral teeth on the postpetiole, and presence of gastric sculpture.

In the key to Epopostruma species in Shattuck (2000), Epopostruma topendi sp. n. runs to couplet 11. In Shattuck (2007) couplet 12 was modified to accommodate E. inornata Shattuck, and this is further modified below to accommodate this new species.

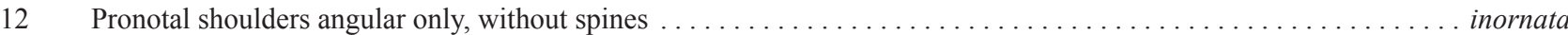

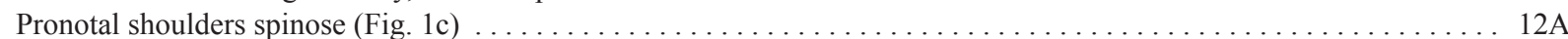

12A Dorsum of promesonotum smooth and shiny medially (Fig. 1c) . . . . . . . . . . . . . . . . . . . . topendi

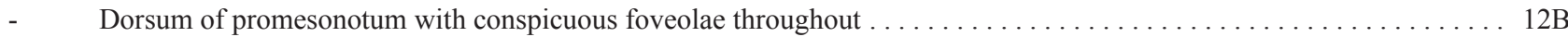

12B In dorsal view, posterolateral corners of the postpetiole spinose, with spines longer than their basal width ........ areosylva

- In dorsal view, posterolateral corners of the postpetiole either unarmed or dentate only, with denticles only as long as their basal

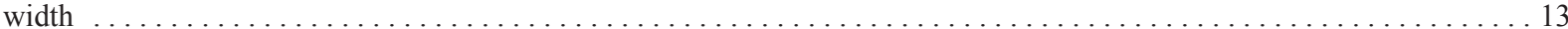

Although the two Top End specimens are extremely similar, they have notable differences in the structure of the petiole and postpetiole (Fig. 2). In the holotype from Nitmiluk National Park, the petiole is rectangular in dorsal view and the anterior corners are conspicuously dentate (Fig. 2a). In the Melville Island specimen, the petiole is broader and dome-shaped anteriorly and has very small and inconspicuous denticles (Fig. 2b). Furthermore, in the Melville Island specimen the anterolateral corners of the postpetiole are more rounded, and the posterolateral teeth are narrower (Fig. 2b). We have conservatively described the two specimens as conspecific due to a lack of additional collections and therefore information on intraspecific variation. However, they possibly represent different species and were considered as such in Andersen et al. (2018). 

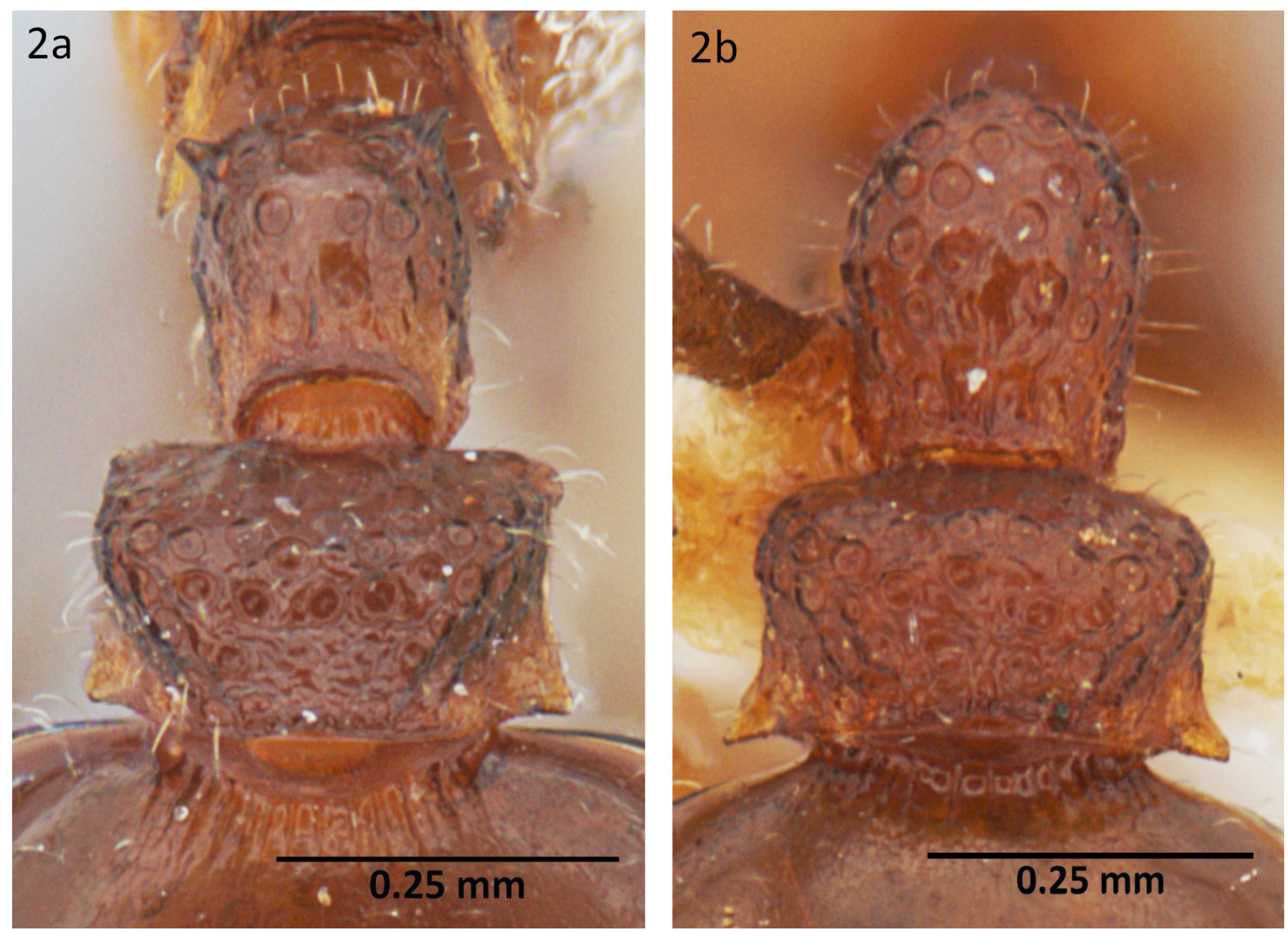

FIGURE 2. Petiole and postpetiole in dorsal view of Epopostruma topendi sp. n.: (a) holotype worker collected from Nitmiluk National Park; (b) paratype worker collected from Melville Island.

\section{Acknowledgments}

We thank the Tiwi Land Council and Jawoyn Association Aboriginal Corporation for permission to access their country. We are most grateful to the NT Department of Primary Industry and Resources for the use of the digital imaging equipment. Comments by William Pettit, Steve Shattuck and an anonymous reviewer improved the manuscript.

\section{References}

Andersen, A.N., Hoffmann, B.D. \& Oberprieler, S. (2018) Diversity and biogeography of a species-rich ant fauna of the Australian seasonal tropics. Insect Science, 25, 519-526. https://doi.org/10.1111/1744-7917.12402

Shattuck, S.O. (1999) s.n. In: Australian ants: their biology and identification. CSIRO Publishing, Collingwood, Victoria, pp. $134-136$. https://doi.org/10.1071/9780643100671

Shattuck, S.O. (2000) The epopostrumiform genus group. In: Bolton, B., The ant tribe Dacetini. Memoirs of the American Entomological Institute, 65, pp. 30-67.

Shattuck, S.O. (2007) New species of Myrmicine ants from Western Australia (Hymenoptera: Formicidae). Zootaxa, 1661, 47-53. 